\title{
The Effects of Cost Management Quality on the Effectiveness of Internal Control and Reliable Decision-Making: Evidence from Thai Industrial Firms
}

\author{
Kanthana Ditkaew
}

\author{
Academic Accounting Department, Faculty of Business Admistration and Liberal Art, \\ Rajamangala University of TechnologyLannaTak,Tak,Thailand,dr.noon@rmutl.ac.th
}

\begin{abstract}
This study investigated the consequences of cost management quality on the effectiveness of internal control and reliable decision-making in Thai industrial firms. With this information, the firms were then tested against performance. A sample of 354 new manufacturing industries in year 2017 of Thailand was chosen and data was collected through mailed questionnaires. Only $340(96.05 \%)$ respondents contributed to the database of this report. The result of ordinary least squares regression revealed that the cost management quality was positively related to the internal control effectiveness and decision-making reliability. In addition, internal control effectiveness and decision-making reliability also had positive effects on firm performance. This implied that without accounting information system quality, a firm had a greater chance of failure. Contributions and suggestions for future research are presented.
\end{abstract}

KEYWORDS: Cost Management Quality (CMQ), Decision-making Reliability, Firm Performance, Internal Control Effectiveness

\section{Introduction}

Thailand's industrial sector has tended upwards as it could be observed from economic situations of industrial firms in Thailand. The industrial product index (IPI) increased by $1.58 \%$ in 2016/17. Furthermore, growth of industrial sector in the first three quarters (Q1, Q2, and Q3) of 2017 resulted from increased import and global economic recovery. Regarding the trend in 2018, it was expected that reliability of industrial sector will be improved due to continual expansion of national economy that drives huge infrastructure investment of the government, such as MRT (Mass Rapid Transit) projects of Mass Rapid Transit Authority of Thailand and investment in Eastern Economic Corridor (EEC) to elevate industrial economy to be the regional center of manufacturing (Ministry of Industry, 2017).

When manufacturing recovers and grows continuously, serious competition will occur and manufacturers will probably be under pressure to adjust the product price to gain profit. Price reduction is not enough to bring success to industrial sector. However, the key success factor in business is cost management quality because management of manufacturing cost is a process of resource allocation to add more value to products by emphasizing effective use of manufacturing cost. Cost management is an important tool to increase business competitive potential as executives have to consider and collect detailed information of occurred cost as well as cutting down unnecessary expenses to reduce manufacturing cost. Therefore, cost management is crucial and executives should pay attention to it in order to obtain accurate cost information that can be used for administration, decision-making, and effective internal control to achieve the highest organizational goals.

Given this background, this paper provides cost management quality perspective that is specific and based on studies in consequence of cost management quality (CMQ) considerations. CMQ provides managerial accounting information to internal control agents to make decisions reliably and efficiently. This study focused on how performance of a sample of Thai manufacturing industries responded to the influence of CMQ. With this in mind, the two related research questions are presented as follows:

- How does CMQ affect effectiveness of internal control and decision-making reliability?

- How do consequences of CMQ affect firm performance?

Therefore, the objectives of this study are to: (1) investigate the effects of CMQ on internal control effectiveness and decision-making reliability; (2) examine the influences of internal control effectiveness and decision-making reliability on firm performance. 


\section{Literature Review and Conceptual Model}

As depicted in figure 1, a conceptual model was constructed to identify how CMQ affects internal control effectiveness and decision-making reliability. Then, internal control effectiveness and decision-making reliability were tested on how they affected firm performance. To link the variables of the model logically, the conceptual model was delineated by a resource-based view of the firm.

Resource-Based View of the firms (RBV)

The concept of resource-based view of the firms (RBV) illustrated how to establish sustainable competitive advantages of organizations from resources which are rare, valuable, hard or impossible to imitate or duplicate, and difficult to substitute (Barney 1991). This concept, nowadays, is extremely popular because organizations having resources, capability, unity, and specialty over rivals will become successful. According to Barney (1991), and Kim and Oh (2004), resources of an organization comprise competency, assets, capability, information, and knowledge; therefore, differences in terms of organizations' resources enable different opportunities to grow and create competitive advantages. In this research, cost management is useful information for executives of industrial sector in the highly competitive era. Information is a vital resource in the organization as it is capable of creating competitive advantages. Competitive advantages of Porter (2008) are results of four factors of resources mentioned above. This research, thus, indicates that having information about effective cost management, organizations in industrial sector possess (1) a resource that is valuable and helpful in decreasing weaknesses in product and service price setting, and operating cost. (2) Information about effective cost management is rare because each organizational culture has different context which is strength of the firm. (3) Imitation in firms is difficult as a result of firm differences. This means that organizations can create information about effective cost management while competitors cannot duplicate, reproduce, and (4) substitute it because this information leads to value adding for customers and ultimate customer satisfaction. The CMQ framework was formulated from the RBV which controlled and applied resources and capabilities to provide competitive information. Having information on their hands, managers obtain some benefits because they can control the organization's processes with produced information, ensure effective internal control, and make meaningful decisions. These factors increase the organization's competitive advantages.

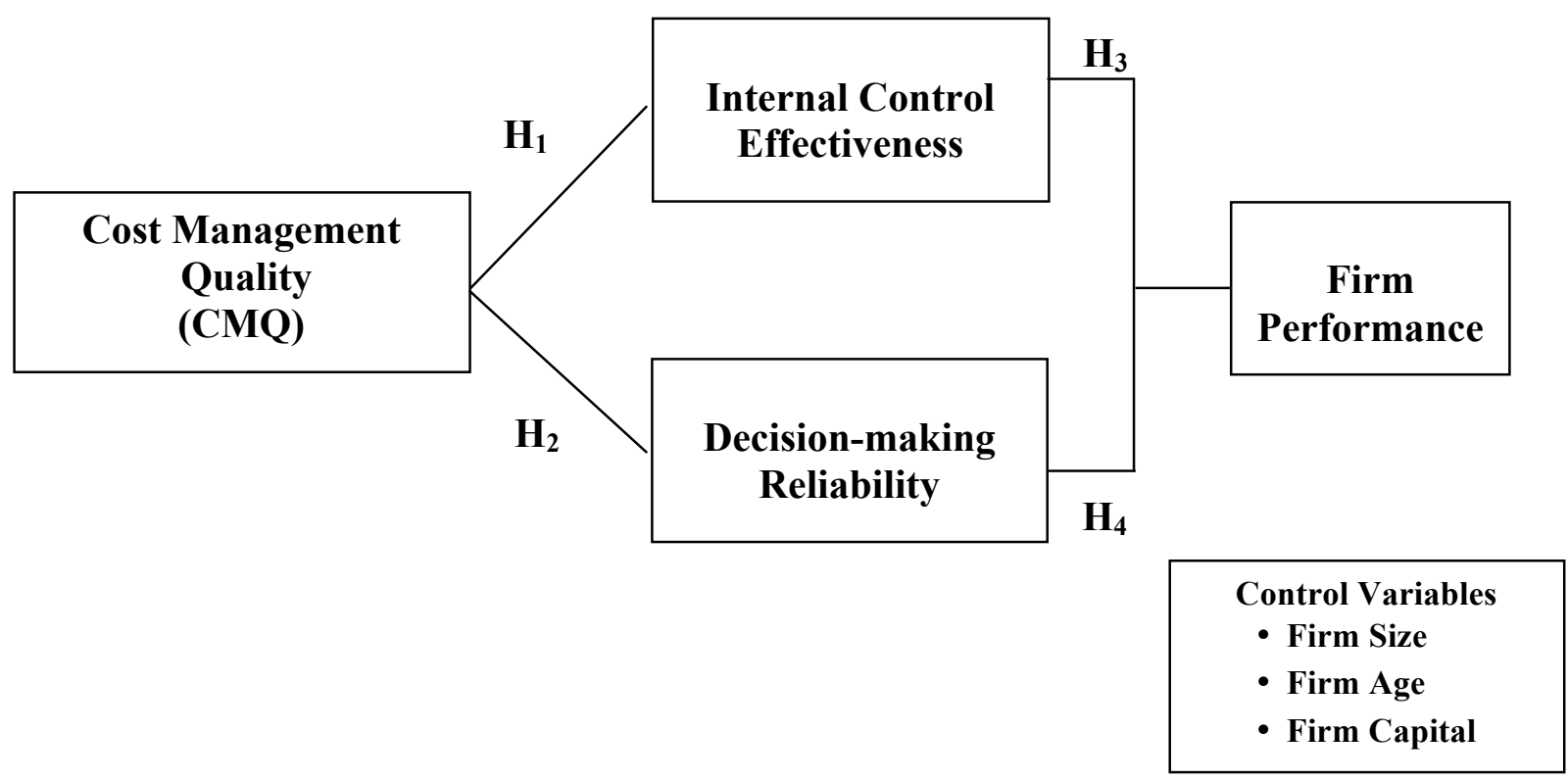

Figure 1. Conceptual Model Of Cost Management Quality (Cmq) In Thai Industrial Firms 


\subsection{Concept of Cost Management Quality (CMQ)}

Cost data is significantly important for planning, commanding, and controlling. Executives must pay attention to cost data of product or service whether it is self-production or trading. It is necessary to know about recording and calculating systems which are accurate, reliable, and useful for business decision-making of the users, such as price setting, cost-volume-profit analysis, break-even analysis, etc. It is also related to controlling cost and expenses efficiently to gain the largest business profit. Cost is a resource with value measured by monetary unit paid for materials, products, and services. Materials, products, and services obtained are proceeded to create maximum benefits and returns for business in the present and future. Occurred cost are both expired costs and unexpired costs. Based on objectives of consideration and administrative use, costs can be categorized in many forms and types to correspond with operation and resource allocation as cost management to achieve the greatest operational success (Finney et al. 2008; Hooley et al. 2005).

Cost management, defined in most studies, concerns with investment in projects to gain returns, for example, the study of Botín and Vergara (2015) claimed that management of operating costs is necessary in building sustainability of economy. Consequently, activity-based costing (ABC) and PDCA's Deming cycle have been applied to develop a cost management system for continual improvement of operation and efficient reduction of cost. Henri et al. (2016) also examined cost management strategies and overall financial operations of organizations with data collection from 319 manufacturing-related firms of Canada. The study found that cost management has significantly positive relation with overall financial operations and is also considered as a long-term strategy to improve supply chain systems and manufacturing of different cost structure.

Hussin et al. (2013) investigated necessary cost management skills for owners of SMEs as they found that SME owners in Malaysia lacked of cost management skills, while the Malaysian government encouraged cost management trainings. Cost management is important for enterprises as follows: (1) firms are able to negotiate price with buyers to create sustainable profit; (2) it helps reduce operational risks; (3) accurate prediction of activity cost control deviation of manufacturing and operation; and (4) correct cost estimation enables firms to control stocked products administration effectively. This paper investigated firms' effective cost management from managerial accounting perspective based on concepts of Hussin et al. (2013) and Staiculescu (2012). Effective cost management in this paper, thus, means correct estimation of cost, accurate cost analysis, and actual manufacturing cost data, which enable internal control effectiveness and decision-making accuracy that further yield satisfying, sustainable performance of organization.

\subsection{Consequences of $C M Q$}

\subsubsection{Internal Control Effectiveness}

Internal control is a principle of security control and consolidation of organizations (Chong et al.2018). The Committee of Sponsoring Organizations of Treadway Commission (COSO) contributed funds for investigation, research, and development of suitable internal control standards (2008) and defined internal control as a process generated by committee, executives, and personnel to assure reasonable accomplishment of objectives in terms of operation, reporting, and conforming to regulations. Furthermore, Romney et.al. $(2009,222)$ interpreted internal control as an operational process specified to establish reasonable assurance among executives, managers, and personnel to internal control objectives as follows: to keep and secure business assets from damage; to certify accuracy and reliability of information reflecting fair value of assets; to support efficiency of operation; to assure firm operation based on proposed budget plan; to operate according to established policies of administrative section; and to enforce relevant legal rules and regulations in firm operation. To summarize definitions mentioned above, internal control is a policy, a plan, and a process of operation systematically designed to create reasonable assurance that committee, executives, and every employee will achieve organizational 
purposes and goals of: asset security; accuracy and reliability of recorded accounting reports and accounting information; effective operation support; and legal rules and regulations strictly conformed by organizations. Previous studies about internal control are related to data exposure, for example, researches of Kelly and Tan (2017); Chong et al. (2018); Bryan (2017) claimed that exposure of financial data has a significant effect on internal control. As a result, this research considered that having useful, accurate, and reliable cost data; and knowing actual cost data lead to firms' internal control effectiveness to secure and allocate manufacturing resources efficiently. Correct and reliable information reflects assets' fair value, supports effective operation, and assures firm operation based on proposed budget plan. Therefore, hypothesis 1 was formulated:

\section{Hypothesis 1: An organization with CMQ will achieve internal control effectiveness.}

\subsubsection{Decision-making Reliability}

Making decisions is a crucial role of executives in running an organizational business. Consequently, obtaining good information and having tools that can access, collect, and analyze data help executives consider several options correctly and quickly. Moreover, it helps solve problems effectively and make optimal decisions.

Decision-making is defined as choosing an action course among alternatives. The keys to efficient decision-making are generation, evaluation, and solutions selected in a rational way. Because the world is moving towards opening more global markets, the necessity of information as being timely, reliable, and easily accessible will be essential. Additionally, decision-making is a highly dynamic process which is complex; redolent with feedbacks and contingencies; full of search detours, information gathering, and information ignoring fueled by fluctuating uncertainty, fuzziness, and conflict (Zeleny, 1981). This study indicated that accuracy of executives' decision-making, more or less, partly depends on quality of cost management. Effective cost management in this study demonstrated information as being relevant, reliable, complete, accurate, clear, concise, timely, understandable, accessible, verifiable, economical, flexible, and secure in order to strengthen decision-making reliability.

Therefore, in this paper, decision-making reliability was defined as a process of decision that is made clearly and correctly from various alternatives. To make a decision, when one of the alternatives is selected, the underlying comprehensiveness leads to improving the advantage in achieving the goal (Talaulicar et. al., 2005). This is because CMQ is considered as an important organizational mechanism that is critical for effective management of decisions and control in organizations (Sajady et. al., 2008). Therefore, the role of CMQ supports the quality of cost information as correct, responsive, flexible, and relevant. It can be used in problem analysis and clarification of problems. When making a decision, the alternatives are divided and evaluated by weighing accounting information in each alternative. Finally, the best choice is selected to optimize organizational performance. Accordingly, CMQ provides cost information for decision-making; the characteristics of information currently prepared can help decision makers seek more alternatives to the solution of the problem in hand. Accessibility to information related to the main transactions of an organization leads to categorized detailed information facilitating decisionmaking in any difficult situation (Mia and Chenhall, 1994). This decision-making process uses accounting information and the decision maker's knowledge and skills to yield a successful decision (O'Donnell and David, 2000). Thus, hypothesis 2 was formulated:

\section{Hypothesis 2: An organization with CMQ will achieve decision-making reliability.}

\subsubsection{Internal Control Effectiveness and Firm Performance}

Previous research, Chong et. al. (2018), identified that internal control concept aims to manage safety and health through safety assessment and control by management of production line (Tinmannsvik and Hovden, 2003). A systematic internal control strategy can help manufacturers put essential risk management control in place. Additionally, Bottani (2009) said that lack of internal control damages the firm's internal working routine, and thus causes poor safety performance. The enforcement of internal 
control is necessary to monitor and follow up closely on preventive measures of hazards and risks in order to avoid the occurrence of workplace accidents. Internal control can reduce risks, protect business operation from fraud or dishonesty, and enhance firm performance as demonstrated by its financial statement. Arens et al. (2006) defined fraud as the intentional misstatement of a financial statement. As Lougee and Marquardt (2004) found that firms with low generally accepted accounting principles (GAAP) earnings are more likely to disclose pro forma earnings consistent with motivations to reflect the firm's performance accurately. Prior experimental research in other financial statement presentation contexts (such as the reporting of comprehensive income) reveals that such presentation choices can affect the costs for users to identify, interpret, and weigh the implications of reported items for the firm (e.g., Hirst and Hopkins, 1998; Maines and McDaniel, 2000). Riedl and Srinivasan (2007) found that evidence is consistent across a range of specifications and special items highlighted on the income statement are more transitory than those revealed only in the footnotes. For most special items, these results are consistent with this presentation reflecting the strength of performance in a firm. Hypothesis 3 was formulated:

\section{Hypothesis 3: An organization with internal control effectiveness will achieve firm performance.}

\subsubsection{Decision-making Reliability and Firm Performance}

Decision-making reliability as a strategy is both effective and efficient in the decision process. It reflects, from its process, comprehensiveness of the problems. The strategy is seen as a rapid decision, timely responding to changing events and creating a competitive advantage (Talaulicar et al., 2005). Research of Abubakar et al. (2017) referred to knowledge management and decision-making process as factors affecting firm performance. Decision-making process is an important variable in the conceptual framework that supports and promotes organizational performance. The process includes identifying the problem clearly. The problem is divided into various alternatives to be evaluated carefully in order to rank the optimization of each alternative and then the best alternative is selected rapidly for making a decision. This process is related to strategic decision effectiveness and firm performance outcome (Dean and Sharfman, 1996). For this reason, executives and managers can make effective decisions to enhance operational control activities to ensure the execution of specific tasks, such as scheduling production, controlling inventory, and extending credit. In the process, managers make efficient decisions to deal with formulating budget, implementing capital plans, developing human resource practices, and improving products. The strategic planning decision influences performance of acquisition, use, and disposition of resources to achieve goals and policies that affect firm performance. CMQ provides accounting information used in effective decision-making that affects business operation and all functions leading to enhance performance. Therefore, hypothesis 4 was postulated:

\section{Hypothesis 4: An organization with decision-making reliability will achieve firm performance.}

\section{Research Methodology}

According to relevant literature, in Thailand, there is an opportunity to study the field of managerial accounting (MA), especially cost management quality (CMQ). Few have researched the MA issues in Asia Pacific region, but none has researched Thailand. In this region, most studies have been undertaken in Australia, New Zealand, Malaysia and, to a lesser extent, China and Hong Kong. Here are opportunities to study CMQ in the context of Thailand. Thus, the motivation of this study was to examine the consequences of CMQ in the context of Thailand.

\subsection{Population and Sample}

In this study, the population and sample were newly constructed manufacturing firms in year 2017, which were granted permissions to run businesses. The key informants were accounting managers of the new Thai manufacturing firms. The database was drawn from the website of Department of Industrial Works, 
http://www.diw.go.th, where there were 2,453 listed manufacturing firms. Therefore, for collecting data, the sample used in the study equals 354 new manufacturing firms listed officially (Krejcie and Morgan, 1970).

\subsection{Data Collection}

The data was collected from questionnaires. The questionnaires were constructed using lessons from empirical studies in the literature. The questionnaires were sent by mail to the accounting manager of each firm. The managers were asked to provide data for this study and return it by mail. After one month, 340 responses were received from the total of 354 questionnaires. The effective response rate was $96.05 \%$. By comparison, the mail survey response rate of Aaker, Kumer, and Day (2001) was approximately $20 \%$. Therefore, the response rate of this study was considered acceptable.

Additionally, the non-response bias was investigated by t-test; responses from the first 170 and last 170 returned questionnaires were tested. The demographic variables were business type, current operation capital, employees in the organization, operational years, sale amount and other revenue's average per year. The results confirmed that the means of demographic variables of the two groups had no significant difference at 95\% confidence level. Therefore, it implied that the questionnaires had a non-response bias. Thus, there was no systematic difference in who responded and who did not (Armstrong and Overton, 1977).

\subsection{Reliability and Validity}

The reliability of the collected data was tested by Cronbach's $\alpha$ (alpha) to measure internal consistency of respondents' answers for all the items in the questionnaires. Each construct was measured by multi-item 5-point Likert scale. Table 1 shows alpha coefficients greater than .70, consistent with the assertion that the coefficients should have values greater than .70 (Nually, 1978). Alpha coefficients of constructs had values ranging from .74 to .88: the lowest coefficient (.74) for firm performance and the highest coefficient (.88) for decision-making reliability. That is, internal consistency for all constructs was good for the measures used in this study. Factor analysis was employed to test construct validity to direct contents in the study. Items were used to measure each construct that was extracted to be only one principal component. Table 1 shows factor loading of each construct with a value greater than .70 (range from 0.72 to 0.92 ). Thus, the construct validity of this study was tapped by items in the measure as theorized. That is, factor loading of each construct should not be less than .4 (Hair et al., 2006).

Table 1. Factor Loading and Alpha Coefficients OF Constructs

\begin{tabular}{lcc}
\hline Constructs & Factor Loading & Alpha Coefficient \\
\hline & & \\
Cost Management Quality (CMQ) & $.76-.90$ & 0.87 \\
Internal Control Effectiveness (ICE) & $.72-.82$ & 0.80 \\
Decision-making Reliability (DMR) & $.78-.91$ & 0.88 \\
Firm Performance (FP) & $.76-.92$ & 0.74 \\
\hline
\end{tabular}

\subsection{Statistical Technique}

Basic data analysis of sample and variables were mean, standard deviation and correlation coefficient. Regression analysis was employed to analyze the relationship between dependent variables and independent variables. Ordinary least squares (OLS) regression analysis was used for testing hypotheses. From the relation model and the hypotheses, the following three model equations were formulated:

Equation 1: ICE $=\beta_{01}+\beta_{1} \mathrm{CMQ}+\beta_{2} \mathrm{FS}+\beta_{3} \mathrm{FA}+\beta_{4} \mathrm{FC}+\varepsilon$

Equation 2: DMR $=\beta_{02}+\beta_{5} \mathrm{CMQ}+\beta_{6} \mathrm{FS}+\beta_{7} \mathrm{FA}+\beta_{8} \mathrm{FC}+\varepsilon$

Equation 3: FP $=\beta_{03}+\beta_{9} \mathrm{ICE}+\beta_{10} \mathrm{DMR}+\beta_{11} \mathrm{FS}+\beta_{12} \mathrm{FA}+\beta_{13} \mathrm{FC}+\varepsilon$ 
CMQ is cost management quality; ICE is internal control effectiveness; DMR is decision-making reliability; FP is firm performance; FS is firm size; FA is firm age; FC is firm capital; $\beta_{i}$ are regression coefficients; and $\varepsilon_{\mathrm{i}}$ is an error term.

\section{Results and Discussion}

Table 2 shows the correlation matrix for all variables. To check multicollinearity problems among independent variables, variance inflation factors (VIF), ranging from 1.03-8.89, were used well below the cut-off value of 10 recommended by Hair, et al., (2006). As a result, there were no significant multicollinearity problems confronted in this study.

Table 2. Descriptive Statistics and Correlation Matrix

\begin{tabular}{lllcc}
\hline Constructs & CMQ & ICE & DMR & FP \\
\hline Mean & 4.02 & 3.76 & 4.40 & 3.41 \\
Standard Deviation & 0.50 & 0.55 & 0.57 & 0.62 \\
Cost Management Quality (CMQ) & 1.00 & & & \\
Internal Control Effectiveness (ICE) & $0.33^{* *}$ & 1.00 & & \\
Decision-making Reliability (DMR) & $0.41^{* *}$ & $0.55^{* *}$ & 1.00 & \\
Firm Performance (FP) & $0.42^{* *}$ & $0.38^{* *}$ & $0.32^{* *}$ & 1.00 \\
\hline \hline
\end{tabular}

*** Correlation is significant at the .01 level (2-tailed).

** Correlation is significant at the .05 level (2-tailed).

Table 3. Results of Ols Regression Analysis

\begin{tabular}{|c|c|c|c|}
\hline \multirow[b]{2}{*}{ Independent Variables } & \multicolumn{3}{|c|}{ Dependent Variables } \\
\hline & $\begin{array}{c}\text { ICE } \\
1 \\
\end{array}$ & $\begin{array}{c}\text { DMR } \\
2 \\
\end{array}$ & $\begin{array}{c}\mathbf{F P} \\
\mathbf{3} \\
\end{array}$ \\
\hline Cost Management Quality (CMQ) & $\begin{array}{l}.18 * * * \\
(.07)\end{array}$ & $\begin{array}{l}.12 * * \\
(.07)\end{array}$ & \\
\hline Internal Control Effectiveness (ICE) & & & $\begin{array}{l}.33^{* * *} \\
(.04)\end{array}$ \\
\hline Decision-making Reliability (DMR) & & & $\begin{array}{l}.48^{* * *} \\
(.04)\end{array}$ \\
\hline Firm Size (FS) & $\begin{array}{l}.05 \\
(.04) \\
-.06\end{array}$ & $\begin{array}{l}.08 \\
(.04) \\
-.15\end{array}$ & $\begin{array}{l}-.10 \\
(.03) \\
-.35\end{array}$ \\
\hline Firm Age (FA) & $\begin{array}{l}(.24) \\
.18\end{array}$ & $\begin{array}{l}(.18) \\
.17\end{array}$ & $\begin{array}{l}(.19) \\
-.10\end{array}$ \\
\hline Firm Capital (FC) & $(.07)$ & $(.06)$ & $(.03)$ \\
\hline Adjusted $\mathrm{R}^{2}$ & .42 & .57 & .58 \\
\hline
\end{tabular}

\subsection{Impacts of CMQ on Its Consequences}

Table 3 presents the results of OLS regression analysis, the effects of CMQ on internal control effectiveness (ICE) and decision-making reliability (DMR). The results showed that CMQ had a significantly positive effect on internal control effectiveness (Model 1: $\beta_{1}=0.18, \mathrm{p}<0.01$ ). Moreover, the results also said that CMQ exerts a significantly positive influence on decision-making reliability (Model 2: $\beta_{5}=0.12, p<0.05$ ). Thus, hypothesis 1 
and hypothesis 2 were supported. This corresponds with studies demonstrating that financial data exposure has a significant effect on internal control (Kelly and Tan, 2017; Chong et al., 2018; Bryan, 2017). In other words, having useful, accurate, and reliable cost data; and knowing actual cost data lead to firms' internal control effectiveness to secure and allocate manufacturing resources efficiently. Correct and reliable information reflects assets' fair value, supports effective operation, and assures firm operation based on proposed budget plan. Cost management quality is a vital tool used by executives when making decisions to yield the best option in accurate and reliable decision-making (Sajady et. al., 2008). For Model 3, it was used for testing the effects of internal control effectiveness and decision-making reliability on firm performance. The results of OLS regression analysis provided evidence that both internal control effectiveness and decision-making reliability had significantly positive effects on firm performance (Model 3: $\beta_{9}$ $=0.33, \mathrm{p}<0.01, \beta_{10}=0.48, \mathrm{p}<0.01$ ). Internal control reduced risk and protected from fraud or dishonesty in business operations and later enhanced the firm's performance demonstrated by a financial statement, strengthened internal control, and regulated accounting professions. This professional environment promotes confidence from the published financial statement through to financial performance (Tacket, 2004). In addition, the strategy is seen as rapid decisions responding to timely changing events and creating a competitive advantage (Talaulicar et al., 2005). Therefore, hypothesis 3 and hypothesis 4 were supported.

\section{Contributions}

As a theoretical contribution, the conceptual model of $\mathrm{CMQ}$, explained by the resource-based view, is information that produces management accounting information reliably (Barney, 2001). It focuses on the influence resources have in order to enhance firm performance. Resources are assets, capabilities, processes, information and knowledge in control of the firm. This study tried to explain CMQ as a resource to produce management accounting information reliably, accurately, relevantly, and timely to execute the internal control effectively and make decisions reliably. The internal control effectiveness and decision-making reliability in turn improved a firm's performance.

As a managerial contribution, internal control effectiveness and decision-making reliability were significantly and positively associated with firm performance. Moreover, CMQ was significantly and positively related to internal control effectiveness and decision-making reliability. Thus, accounting managers should understand and develop cost management to provide information with quality, accuracy, and relevance. Such information should be: easy to understand; supportive of the strategies for more effective operation; able to outperform competitors for survival in the marketplace. Firms with CMQ will achieve internal control effectiveness and decision-making reliability, and therefore enhance firm performance. CMQ can help businesses in the eve of ASEAN to improve their competitive advantages, build corporate intelligence, achieve decision planning, streamline production processes, and gain the competitive edge.

\section{Conclusion, Limitation and Further Research}

The study focuses on the consequences of implementing cost management quality (CMQ) as it affects internal control effectiveness and decision-making reliability. Results found that CMQ was significantly and positively related to internal control effectiveness and decision-making reliability. Internal control effectiveness and decision-making reliability also significantly and positively influenced and enhanced firm performance in turn. Those Thai manufacturing firms reported through the Department of Industrial Works were used as a sample to test the model. The limitations of the study were described as follows. Firstly, the proposed conceptual model was only tested on new firms from the Department of Industrial Works. A study needs to be conducted on other firms as well. Secondly, some of the consequences of CMQ might have been omitted. In further research on the impact of CMQ, new variables should be added, such as effective budgeting, strategic performance measurement, productivity, and other variables. Finally, the antecedents of CMQ should be examined: how antecedents of CMQ such as executive vision and information technology affect CMQ. 


\section{References}

Aaker, D.A., V. Kumar \& G.S. Day. 2001. Marketing Research (7th ed.). New York: John Wiley \& Sons.

Abubakar, A.M., Elrehail, H., Alatailat, M.A., \& Elçi, A. (2017). "Knowledge Management, Decision-Making Style and Oganizational Performance." Journal of Innovation \& Knowledge, Article in Press.

Arens, A.A., Elder, R.J., \& Beasley, M.S. 2006. Auditing and Assurance Services: An Integrated Approach. (11th ed.). New York: Pearson.

Armstrong, J.S., \& Overton, T.A. 1977. "Estimating Nonresponse Bias in Mail Surveys.” Journal of Marketing Research, 14: 396-402.

Barney, J.B. 2001. "Resource-Based Theories of Competitive Advantage: A Ten-Year Retrospective on the Resource-Based View." Journal of Management 27(6): 643-650.

Barney, J.B. 1991. "Firm Resources and Sustained Competitive Advantage." Journal of Management 17(1): 99-120.

Botín, J.A., \& Verara, M.A. 2015. "A Cost Management Model for Economic Sustainability and Continuous Improvement of Mining Operations." Resources Policy 46: 212-218.

Bryan, D.B. 2017. "Organized Labor, Audit Quality, and Internal Control.” Advances in Accounting 36: 11-26.

Chong, H.C., Ramayah, T., Subramaniam, C. 2018. "The Relationship Between Critical Success Factors, Internal control and Safety Performance in the Malaysian Manufacturing Sector." Safety Science 104: 179-188.

Dean, W. J., \& Sharfman, P.M. 1996. "Does Decision Process Matter? A Study of Strategic Decision-Making Effectiveness. Academy of Management Journal 39: 368-391.

Finney, R.Z., Lueg, J.E., \& Campbell, N.D. 2008. Market Pioneers, Late Movers, and the Resource-Based View (RBV): A Conceptual Model. Journal of Business Research 61 (9): 925-932.

Hair, J.F., Black, W.C., Babin, B.J., \& Anderson, R.E. 2010. Multivariate Data Analysis: A Global Perspective. Upper Saddle River: Pearson.

Henri, Jean-François, Boiral, O., \& Roy, Marie-Josèe. 2016. "Strategic Cost Management and Performance: The Case of Environment Costs." The British Accounting Review 48: 269-282.

Hirst, D.E., \& Hopkins, P.E. 1998. "Comprehensive Income Disclosures and Analysts' Valuation Judgments." http://dx.doi.org/10.2139/ssrn.63588.

Hooley, G.J., Greenley, G.E., Cadogan, J.W. \& Fahy, J. 2005. “The Performance Impact of Marketing Resources.” Journal of Business Research 58 (1): 18-27.

Hussin, M.R.A., Alias, R.A., \& Ismail, K. 2013. "An Action Research Approach for the Development of Cost Management Skills Training Program Among the Owners of Small and Medium Enterprises (SMEs) In Malaysia." Procedia-Social and Behavioral Sciences 91: 515-521.

Kelly, K., \& Tan, Hun-Tong. 2017. "Mandatory Management Disclosure and Mandatory Independent Audit of Internal Control: Evidence of Configure Information Processing by Invertors." Accounting, Organizations and Society 56: 1-20.

Kim, B.Y. \& Oh, H. 2004. "How do Hotel Firms Obtain a Competitive Advantage?" International Journal of Contemporary Hospitality Management 16 (1): 65-71.

Krejcie, R.V., \& Morgan, D.W. 1970. "Determining Sample Size for Research Activities." Educational and Psychological Measurement 30 (3): 607-610.

Lougee, B.A., \& Marquardt, C.A. 2004. "Earnings Informativeness and Strategic Disclosure: An Empirical Examination of "Pro Forma" Earnings." The Accounting Review 79(3): 769-795

Maines, L.A., \& McDaniel, L.S. 2000. "Effects of Comprehensive-Income Characteristics on Nonprofessional Investors' Judgments: The Role of Financial-Statement Presentation Format." The Accounting Review 75 (2): 179-207.

Mia, L., \& Chenhall, R. H. (1994). "The Usefulness of Management Accounting Systems, Functional Differentiation and Managerial Effectiveness." Accounting Organization Society 19: 1-13.

Ministry of Industry. (2017). Industrial Economic Status Reporting. [Online]. Available: www.oie.go.th. [2018, January 14].

Nually, J. C. 1978. Psychometric Theory. (2nd ed.). New York: McGraw-Hill Book Company.

O'Donnell, E., \& David, J. S. (2000). "How Information Systems Influence User Decisions: A Research Framework and Literature Review." International Journal of Accounting Information Systems 1(3): 178-203.

Porter, M.E. 2008. "The Five Competitive Forces that Shape Strategy.” Harvard Business Review, January: 79-93.

Riedl, E.J, \& Srinivasan, S. 2007. "Signaling Firm Performance Through Financial Statement Presentation: An Analysis Using Special Items." [Online]. Available: http://ssrn.com/abstract=923898. [2018, January 24].

Romney, Marshal, J.P. \& Steinbart. 2009. Accounting Information System. (10th Ed). New Jersey: Prentice-Hall-Person.

Sajady, H., Dastgir., \& Nejad, H.H. 2008. "Evaluation of The Effectiveness of Accounting Information Systems." International Journal of International Science and Technology 6 (2): 49-59.

Staiculescu, O. 2012. "A New Vision of Quality Cost: An Essential Optimization Tool for Managerial Accounting." ProcediaSocial and Behavioral Sciences 62: 1276-1280.

Talaulicar, T., Grundei, J., \& Werder, A. V. 2005. "Strategic Decision Making in Start-Ups: The Effect of Top Management Team Organization and Processes on Speed and Comprehensiveness." Journal of Business Venturing 20: 519-541.

Tinmannsvik, R. K. \& Hovden, J. 2003. "Safety Diagnosis Criteria - Development and Testing." Safety Science 41: 575-590. 
Wu, S. H. 1998. “The Impact of Knowledge Circulation on Industrial Innovation.” Symposium on Industry Management. Zeleny, M. 1981. "On the Squandering of Resources and Profits via Linear Programming." Interface 11 (5): 101-107. 